\title{
Functional network connectivity of the control and epileptic hippocampus
}

\author{
Ivan Soltesz \\ From Twentieth Annual Computational Neuroscience Meeting: CNS*2011 \\ Stockholm, Sweden. 23-28 July 2011
}

With the rapid rise in our knowledge about the structural and functional properties of hippocampal microcircuits, it has become possible to closely integrate experimental findings with large-scale, anatomically and biophysically realistic computational simulations of control and epileptic neuronal networks with unprecedented precision and predictive power. We are developing full-scale realistic network models of the control and injured temporal lobe in order to investigate fundamental questions related to normal hippocampal microcircuit function and the mechanistic bases of epilepsy. I review the conceptual framework and biological basis of model development and show specific applications, including new computational and experimental results concerning the phase-related firing of various interneuronal subtypes during learning and memoryrelated hippocampal network oscillations and the roles of aberrant hyper-connected hub-like neurons in seizures. The talk will highlight the unprecedented predictive and analytic power of increasingly user-friendly, freely shared, highly realistic, large-scale computational models in understanding normal circuit function and temporal lobe epilepsy.

Submit your next manuscript to BioMed Central and take full advantage of:

- Convenient online submission

- Thorough peer review

- No space constraints or color figure charges

- Immediate publication on acceptance

- Inclusion in PubMed, CAS, Scopus and Google Scholar

- Research which is freely available for redistribution 